\title{
Legal Liability in Iatrogenic Orbital Injury
}

\author{
Peter F. Svider, BA; Olga Kovalerchik, BA; Andrew C. Mauro, BA; Soly Baredes, MD, FACS; \\ Jean Anderson Eloy, MD, FACS
}

\begin{abstract}
Objectives/Hypothesis: In this study, we detailed factors governing legal outcomes in iatrogenic orbital injury, with the purpose of discussing strategies to minimize liability and enhance patient safety.

Study Design: Retrospective analysis.

Methods: Jury verdict and settlement reports were searched from publically available federal and state court records using the Westlaw database (Thomson Reuters, New York, NY). After exclusion of nonrelevant cases, 20 cases of iatrogenic orbital injuries were examined for factors such as legal outcome, damages awarded, defendant specialty, alleged causes of malpractice, and patient demographic information.

Results: The majority $(60.0 \%)$ of cases were resolved in the defendant's favor. Payment was considerable for the cases decided in support of the plaintiff, averaging \$1.13 million. Out-of-court settlements averaged \$1.78 million (range, $\$ 487,500-$ $\$ 3.9$ million), whereas jury-awarded damages averaged $\$ 472,661$ (range, $\$ 75,000-\$ 763,214$ ). Complications stemming from endoscopic sinus surgery were most common (50.0\%). Diplopia was the most common medical complaint (50.0\%), whereas permanent deficits and having to undergo additional surgery were each present in $65.0 \%$ of cases.

Conclusions: The potential for permanent sequelae of iatrogenic orbital injury makes this complication susceptible to malpractice litigation. Otolaryngologists were the most common defendants. Although cases were resolved in the defendant's favor $60 \%$ of the time, payments made were considerable, averaging $\$ 1.13$ million. Steps to minimize liability and improve patient safety include an informed consent process explicitly listing risks, including diplopia and blindness, and obtaining timely ophthalmology consultation when a complication is recognized.
\end{abstract}

Key Words: Liability, malpractice, iatrogenic orbital injury, negligence, malpractice trial.

Level of Evidence: NA

Laryngoscope, 123:2099-2103, 2013

\section{INTRODUCTION}

Several considerations have affected strategies for dealing with the increasing prevalence of malpractice litigation over the previous few decades. The rise in litigation has contributed significantly to health care costs, both directly and indirectly, adding between $\$ 6.5$ and $\$ 10$ billion annually. ${ }^{1-6}$ Direct costs include those associated with legal defense, jury damages awarded, and out-of-court settlements. Additionally, malpractice insurance premiums have risen considerably in recent years, with one analysis estimating the average policy for a practicing physician to cost nearly $\$ 25,000$ annually. ${ }^{7}$ Other less obvious costs include

From the Department of Otolaryngology-Head and Neck Surgery (P.F.S., O.K., S.B., J.A.E.), University of Medicine and Dentistry of New Jersey, New Jersey Medical School, Newark, New Jersey, The University of Michigan Law School (A.C.M.), Ann Arbor, Michigan, Center for Skull Base and Pituitary Surgery (s.B., J.A.E.), University of Medicine and Dentistry of New Jersey, New Jersey Medical School, Newark, New Jersey, Department of Neurological Surgery (J.A.E.), University of Medicine and Dentistry of New Jersey, New Jersey Medical School, Newark, New Jersey, U.S.A.

Editor's Note: This Manuscript was accepted for publication December 24, 2012.

The authors have no funding, financial relationships, or conflicts of interest to disclose.

Send correspondence to Jean Anderson Eloy, MD, Associate Professor and Vice Chairman, Director of Rhinology and Sinus Surgery, Department of Otolaryngology-Head and Neck Surgery, UMDNJ-New Jersey Medical School, 90 Bergen St., Suite 8100, Newark, NJ 07103. E-mail: jean.anderson.eloy@gmail.com

DOI: 10.1002/lary.24000 those associated with a rise in the practice of defensive medicine, as well as a decrease in access to health care. ${ }^{8,9}$

Factors in determining legal responsibility have been previously examined in the otolaryngologic surgical literature for topics including, but not limited to, corticosteroid use, ${ }^{10}$ head and neck cancers, ${ }^{11-14}$ and sinonasal disease. ${ }^{1,15}$ Iatrogenic orbital injury is of potential concern to surgeons in several specialties, including otolaryngology, ophthalmology, and plastic surgery. Complications that may considerably impact function and quality of life are very likely in this region given the close proximity of the orbit to critical structures. This, in turn, renders orbital injuries especially susceptible to litigation. Our objective was to comprehensively characterize factors governing legal outcome in iatrogenic orbital injury, with the goal of discussing strategies to diminish liability and augment patient safety.

\section{MATERIALS AND METHODS}

Publically available federal and state jury verdict and settlement reports were searched using the Westlaw legal database (Thomson Reuters, New York, NY), a resource that has previously been used in analyses of litigation related to corticosteroid use,${ }^{10}$ hearing loss,${ }^{16}$ sinonasal disease,${ }^{15}$ facial paralysis,${ }^{17}$ and facial plastic surgery. ${ }^{18}$ Varying commercial vendors collect data from court records and submit them for inclusion to Westlaw. Although some jurisdictions have records only submitted voluntarily by legal professionals who do so with the purpose of predicting outcomes and damages awarded for future cases, other jurisdictions' court records offer nonvoluntarily submitted 
"Medical malpractice" \& "orbital" OR "orbit" OR "lamina
papyracea" OR "orbital lamina" OR "pars orbitalis" OR
"orbital process" OR "orbital surface" OR "lacrimal bone"

80 Initial Results

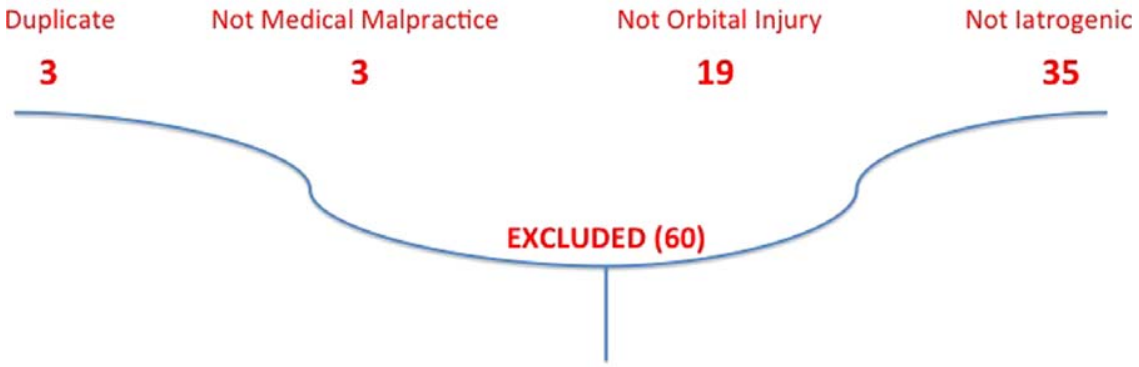

20 Jury Verdicts and Settlements related to latrogenic Orbital Injury
Fig. 1. Westlaw search methodology for jury verdict and settlement reports relevant to iatrogenic orbital injury. [Color figure can be viewed in the online issue, which is available at wileyonlinelibrary.com.] verdict and settlement reports. ${ }^{10,16,17}$ These records are frequently labeled as "confidential," "anonymous," or "John/Jane Doe" in this database. Westlaw research support was contacted by the authors. They were unable to provide specific information as to which jurisdictions offered what level of detail, stressing that this information varied by vendor.

Cases regarding iatrogenic orbital injury, specifically including injuries to the orbital bones or tissues surrounding the eyes, were included using the methodology illustrated in Figure 1. After excluding nonrelevant cases, the 20 jury verdicts and settlements were analyzed for outcome, damages awarded, specialty of defendant, procedure performed, patient demographics, and alleged factors contributing to litigation.

All data were collected in October 2012. Statistical analysis was conducted using a Student $t$ test for comparison of the size of damages awarded with settlement totals (Microsoft Excel; Microsoft Corp., Redmond, WA).

\section{RESULTS}

Twenty cases were included after excluding nonrelevant jury verdicts and settlements (Fig. 1). The cases ranged from 1988 to 2011. The mean patient age was 52.4 years (range, 21-72 years). Sixty percent of the plaintiffs were women. The majority $(60.0 \%)$ of cases were resolved in the defendant's favor (Fig. 2). Among cases resulting in payment, the mean settlement was $\$ 1.78 \mathrm{M}$ (range, 487,500-3.9 million) and trended higher than the mean jury-awarded damages of $\$ 472,661$ (range, 75,000-763,214), although this difference did not reach statistical significance ( $t$ test, $P=.13$ ). Specific factors involved in cases resulting in payment are detailed in Table I.

Rhinologic procedures comprised $60.0 \%$ of iatrogenic orbital injury litigation, with $50.0 \%$ of overall cases caused by endoscopic sinus surgery (ESS) (Fig. 3A). Consequently, otolaryngologists represented the most frequently litigated defendants $(65.0 \%)$, with seven cases resolved in the defendant's favor and six cases resulting in payment (Fig. 3B).

Diplopia was by far the most common medical complaint $(50.0 \%)$, with eye pain, restriction in eye movement, and blindness (complete or partial) also well represented (30.0\% each) (Fig. 4). Other frequent factors cited by plaintiffs as reasons for litigation included having an allegedly permanent deficit as a result of injury

TABLE I.

latrogenic Orbital Injury Litigation Resolved With Payments.

\begin{tabular}{|c|c|c|c|c|c|c|c|c|c|}
\hline Procedure & $\mathrm{A} / \mathrm{S}$ & IC & UP & Repair & Dip & Vis & Perm & Outcome & \$ Amount \\
\hline ESS $^{*}$ & $72 \mathrm{~F}$ & No & No & No & Yes & Yes & Yes & Verdict & 763,214 \\
\hline ESS (ethmoid) ${ }^{*}$ & $\mathrm{~F}$ & No & No & Yes & No & Yes & Yes & Verdict & 652,308 \\
\hline Orb Fx Repair ${ }^{\dagger}$ & $56 \mathrm{M}$ & No & No & Yes & No & No & No & Verdict & 75,000 \\
\hline ESS (ethmoid) ${ }^{*}$ & $M$ & No & No & Yes & Yes & Yes & No & Verdict & 400,121 \\
\hline ESS $^{*}$ & $67 \mathrm{~F}$ & No & No & Yes & Yes & Yes & Yes & Settlement & 487,500 \\
\hline Orb Decomp ${ }^{\ddagger}$ & $21 \mathrm{~F}$ & Yes & No & No & No & Yes & Yes & Settlement & $1,250,000$ \\
\hline ESS $^{\ddagger}$ & $45 \mathrm{~F}$ & No & No & Yes & Yes & Yes & Yes & Settlement & $3,900,000$ \\
\hline Orb Flr Implant & $\mathrm{M}$ & No & No & Yes & No & Yes & Yes & Settlement & $1,500,000$ \\
\hline
\end{tabular}

*Medial rectus transection.

${ }^{\dagger}$ Foreign body left behind.

${ }^{\ddagger}$ Cranial nerve II injury.

$\mathrm{A} / \mathrm{S}=$ age/sex; Dip=diplopia; ESS=endoscopic sinus surgery; IC=alleged deficit in informed consent; Orb Decomp=orbital decompression (endoscopic); Orb FIr Implant=orbital floor implant; Orb Fx Repair=orbital fracture repair; Perm=permanent defect; Repair=required surgical repair; UP=allegedly unnecessary/improper procedure; Vis=visual defect. 


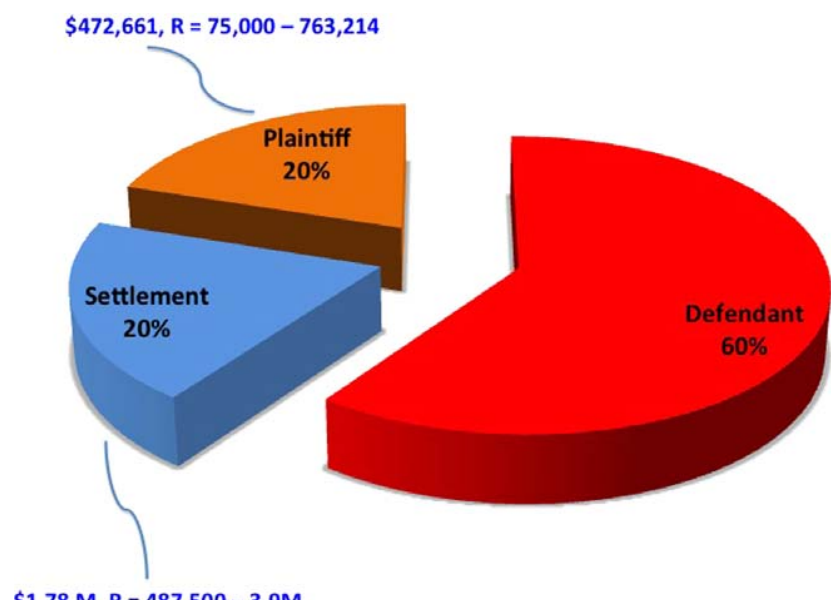

$\$ 1.78 \mathrm{M}, \mathrm{R}=487,500-3.9 \mathrm{M}$

Fig. 2. Outcome profile of iatrogenic orbital injury litigation. Mean and range $(\mathrm{R})$ of settlements and damages awarded listed. [Color figure can be viewed in the online issue, which is available at wileyonlinelibrary.com.]

and having to undergo additional surgery as a result of a complication (65.0\% each) (Fig. 5).

\section{DISCUSSION}

The litigation process is responsible for increased costs passed down to health care consumers, ${ }^{4-6}$ and is widely viewed by physicians as unnecessarily adversarial and unjust. ${ }^{19}$ The considerable size of damages awarded, and the time and costs associated with mounting a legal defense of claims that may be without merit reinforce this perception of unfairness. ${ }^{20}$ In addition to the financial aspects and sense of unfairness regarding the medicolegal system, effects of litigation on reputation among peers and patients are of special importance to practitioners. $^{21}$

The vast majority of surgical malpractice litigation does not make it to trial, with one analysis estimating that $85 \%$ of cases are either dismissed in summary judgment or resolved with an out- of-court settlement. ${ }^{22,23}$ It is unclear if there is any relationship between lawsuits that do progress to the courtroom and the merits of the particular case. ${ }^{24}$ One analysis suggests there is little association between the quality of a claim and the likelihood of settlement or outright dismissal. ${ }^{25}$

In this analysis, litigation related to iatrogenic orbital injury was a medicolegal issue that affected otolaryngologists more frequently than ophthalmologists (Fig. 3). Complications from ESS were present in 10 of 13 (76.9\%) cases involving otolaryngologists, almost exclusively associated with compromise of the lamina papyracea. Additionally, it should be noted that in three of $13(23.1 \%)$ cases involving an otolaryngology defendant, the plaintiff alleged either that the defendant was not qualified to perform the procedure or subsequent repair, or was negligent in not requesting an ophthalmology consult in a timely manner.

These findings emphasize the fact that surgeons should have a comprehensive informed consent process that explicitly describes the ophthalmologic risks associated with rhinologic procedures and have a discussion regarding what plan of action may be taken in the event that the orbital wall is compromised. By specifically outlining the risks noted in Figure 4, surgeons may minimize liability and allow patients to make more informed decisions to undergo procedures or consider alternatives. Additionally, the potential need for reparative procedures after a complication should also be stressed to patients, as
Fig. 3. (A) Outcomes of procedures attributed to orbital injury in malpractice litigation. Blue (bottom) portion of bars represent cases decided in the defendant's favor, red (top) portion of bars represent cases resolved with payment. (B) Defendant specialty, left bar of each cluster represents number of cases resolved with payment; right bar of each cluster represents defendant verdict. Decompress $=$ orbital decompression procedure; ESS = endoscopic sinus surgery; Ophthoophthalmologists; Other Ophtho=ptosis repair, retina repair; Other Rhinologic $=$ nasal polyp surgery, Caldwell-Luc procedure; Otootolaryngologists; Plastic $=$ plastic surgeons; Recon=orbital reconstruction procedures. [Color figure can be viewed in the online issue, which is available at wileyonlinelibrary.com.]

A
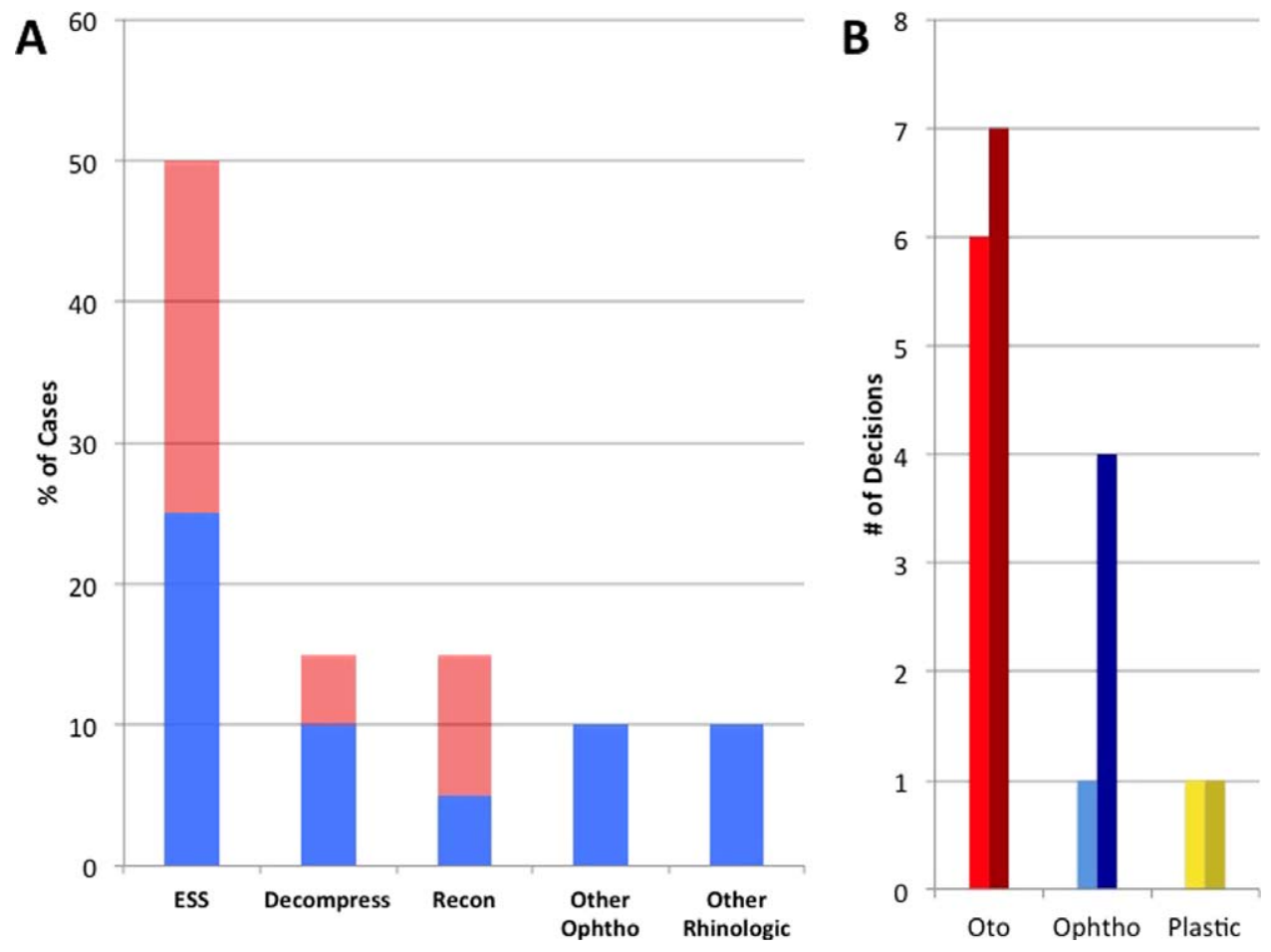


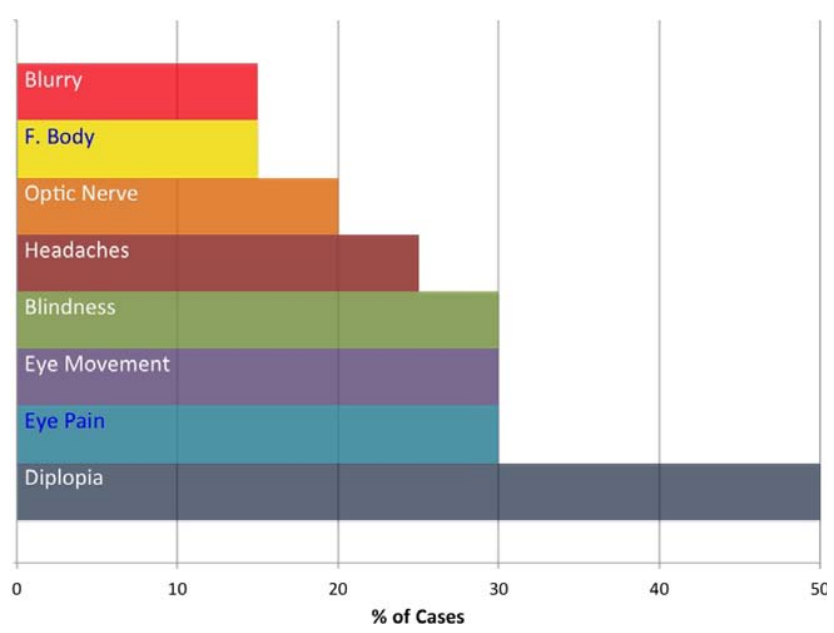

Fig. 4. Most frequent medical complaints involved in litigation. Blindness=both partial and complete blindness; Blurry=blurred vision; F. Body=foreign body left behind intraoperatively; Optic Nerve =optic nerve injury. [Color figure can be viewed in the online issue, which is available at wileyonlinelibrary.com.]

this was a frequent factor in many cases and commonly resulted in payment to the plaintiff $(65.0 \%$, Fig. 5, Table I).

The majority of cases were resolved in the defendant's favor (Fig. 2). The costs were substantial in cases that resulted in payment, with the mean overall payment being $\$ 1.13$ million (Table I). The highest outof-court settlement was $\$ 3.9$ million. In this case, a 45-year-old female undergoing ESS suffered permanent diplopia and blurred vision after the defendant penetrated the lamina papyracea and transected the medial rectus muscle. Aside from complaints of double vision, the plaintiff suffered optic nerve injury, corneal injury, subsequent glaucoma, alleged disfigurement, and reported chronic pain.

The two highest jury awards $(\$ 763,214$ and $\$ 652,308)$ were awarded to patients experiencing complications from ESS. In one of these cases, the defendant surgeon observed orbital fat prolapsed, which limited the ethmoidectomy in progress. Postoperatively, the patient experienced right eye blindness, pain, and swelling, and eventually underwent an emergent orbital decompression performed by the defendant otolaryngologist. Failure to obtain an ophthalmology consult was cited as one of the reasons for the lawsuit.

One notable finding illustrated in Table I was that the two cases with the lowest payment (both were verdicts: $\$ 75,000, \$ 400,121)$ were also the only ones in which the plaintiff did not have a permanent deficit. This further indicates the importance of stressing the risks of permanent injury during the informed consent process preoperatively.

Meeting the threshold for negligence requires several factors beyond proof of a surgical error. To award damages, plaintiffs need to prove four factors to attribute liability: 1) the presence of a duty; 2) deviation from this duty, also known as deviating from the standard of care; 3) harm; and 4) demonstration of causation. ${ }^{26}$ Such rigorous standards likely contribute to the finding that

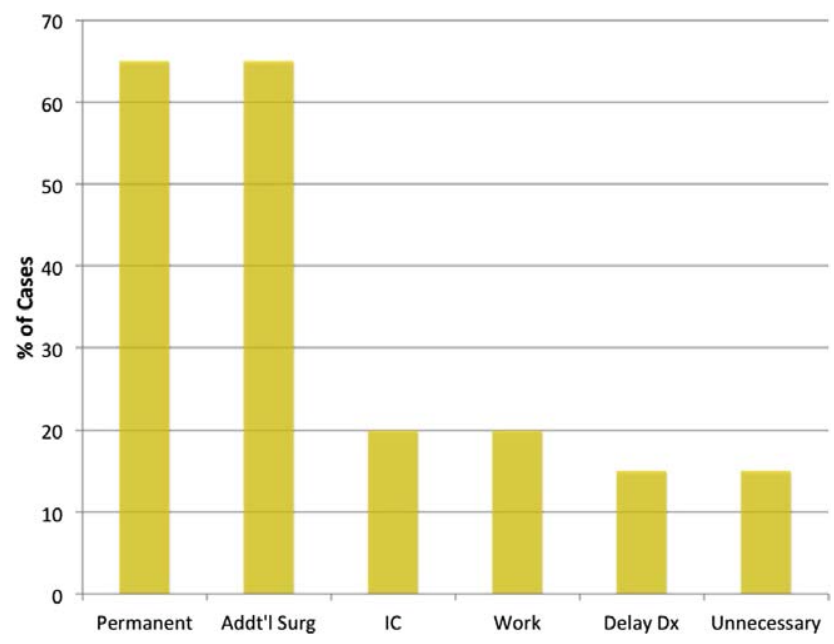

Fig. 5. Most frequent alleged nonmedical factors cited in litigation. Addt'l Surg=required additional surgery for complication; Delay $\mathrm{Dx}=$ failure to recognize complication in a timely manner; $I C=$ perceived deficits in informed consent; Permanent=permanent injury; Unnecessary=allegedly unnecessary/improper procedure; Workemployment affected by injury. [Color figure can be viewed in the online issue, which is available at wileyonlinelibrary.com.]

the majority of cases involving iatrogenic orbital injury were decided in the defendant's favor.

Westlaw is a comprehensive database for outcomes and details in malpractice litigation, which makes it a valuable resource for studying factors in determining legal responsibility. However, there are limitations inherent to its use. Out-of-court settlements were likely under-represented in this analysis, as many do not progress to the point at which they are filed with state and federal courts and become part of publically available records. As such, this may not be the ideal resource for measuring overall prevalence of a case. Additionally, the jury verdict and settlement reports detailed in Westlaw were a heterogeneous source of information, and level of detail varied tremendously, even among cases from the same jurisdiction. Finally, some jurisdictions may only include cases reported by attorneys voluntarily, although with the explicit purpose of disseminating information used for predicting future outcomes and awards. ${ }^{10}$ Despite these drawbacks, however, the rich detail in this resource widely used by legal professionals has been validated through its use in litigation analyses on specific topics such as corticosteroid use ${ }^{10}$ hearing loss, ${ }^{16}$ facial nerve paralysis, ${ }^{17}$ facial plastic surgery, ${ }^{18}$ and sinonasal disease. ${ }^{15}$

\section{CONCLUSION}

The significant potential for permanent sequelae after iatrogenic orbital injury makes these complications especially susceptible to malpractice litigation. Otolaryngologists were the most common defendants in these cases. Although most cases in this analysis were resolved in the defendant's favor, payments awarded were considerable both through out-of-court settlements and damages awarded. By adopting a comprehensive informed consent process that explicitly lists risks, 
including diplopia and blindness, and considering prompt consultation of an ophthalmologist when a complication is recognized, practitioners can diminish liability and potentially enhance patient safety.

\section{BIBLIOGRAPHY}

1. Lynn-Macrae AG, Lynn-Macrae RA, Emani J, Kern RC, Conley DB. Medicolegal analysis of injury during endoscopic sinus surgery. Laryngoscope 2004;114:1492-1495

2. General Accounting Office. Medical liability: impact on hospital and physician costs extends beyond insurance. Washington, DC: General Account ing Office; 1995.

3. Anderson GF, Hussey PS, Frogner BK, Waters HR. Health spending in the United States and the rest of the industrialized world. Health Aff (Mill wood) 2005;24:903-914

4. Brooks RG, Menachemi N, Hughes C, Clawson A. Impact of the medical professional liability insurance crisis on access to care in Florida. Arch Intern Med 2004;164:2217-2222.

5. Nahed BV, Babu MA, Smith TR, Heary RF. Malpractice liability and defensive medicine: a national survey of neurosurgeons. PloS One 2012;7:e39237.

6. Mello MM, Kachalia A, Goodell S. Medical malpractice-april 2011 update. Synth Proj Res Synth Rep. 2011;(21 suppl 1):pii.72097.

7. Hertz BT, Arthurs J. Malpractice rates plateauing. The only thing to fear may be fear itself. Med Econ 2011;88:24-25, 28-29, 32.

8. Medical malpractice litigation raises health-care cost, reduces access, and lowers quality of care. J Med Pract Manage 2004;20:44-51.

9. Hermer LD, Brody H. Defensive medicine, cost containment, and reform. $J$ Gen Intern Med 2010;25:470-473.

10. Nash JJ, Nash AG, Leach ME, Poetker DM. Medical malpractice and corticosteroid use. Otolaryngol Head Neck Surg 2011;144:10-15.

11. Abadin SS, Kaplan EL, Angelos P. Malpractice litigation after thyroid surgery: the role of recurrent laryngeal nerve injuries, 1989-2009. Surgery 2010;148:718-722; discussion 722-723.
12. Lydiatt DD. Cancer of the oral cavity and medical malpractice. Laryngo scope 2002;112:816-819.

13. Lydiatt DD. Medical malpractice and cancer of the larynx. Laryngoscope 2002;112:445-448.

14. Lydiatt DD. Medical malpractice and head and neck cancer. Curr Opin Otolaryngol Head Neck Surg 2004;12:71-75.

15. Lydiatt DD, Sewell RK. Medical malpractice and sinonasal disease. Otolar yngol Head Neck Surg 2008;139:677-681.

16. Reilly BK, Horn GM, Sewell RK. Hearing loss resulting in malpractice litigation: What physicians need to know. Laryngoscope 2013;123:112-117.

17. Lydiatt DD. Medical malpractice and facial nerve paralysis. Arch Otolaryngol Head Neck Surg 2003;129:50-53.

18. Svider PF, Keeley BR, Zumba O, Mauro AC, Setzen M, Eloy JA. From the operating room to the courtroom: a comprehensive characterization of litigation related to facial plastic surgery procedures. Laryngoscope. 2013 Jan 8. doi: 10.1002/lary.23905. [Epub ahead of print]

19. Annas GJ. Doctors, patients, and lawyers-two centuries of health law. $N$ Engl J Med 2012;367:445-450.

20. Mehlman MJ. The shame of medical malpractice. J Leg Med 2006;27:1732.

21. Burkle CM, Martin DP, Keegan MT. Which is feared more: harm to the ego or financial peril? A survey of anesthesiologists' attitudes about medical malpractice. Minn Med 2012;95:46-50.

22. Jena AB, Chandra A, Lakdawalla D, Seabury S. Outcomes of medical malpractice litigation against US physicians. Arch Intern Med 2012;172: 892-894.

23. Jena AB, Seabury S, Lakdawalla D, Chandra A. Malpractice risk according to physician specialty. N Engl J Med 2011;365:629-636.

24. Peters PG Jr. The fairness of malpractice settlements. Regulation 2007;30:30-35.

25. Brennan TA, Sox CM, Burstin HR. Relation between negligent adverse events and the outcomes of medical-malpractice litigation. $N$ Engl $J$ Med 1996;335:1963-1967.

26. Moffett P, Moore G. The standard of care: legal history and definitions: the bad and good news. West J Emerg Med 2011;12:109-112. 